\title{
SIMULATING THE EFFECTS OF ANTHROPOGENIC DISTURBANCES IN LANDSCAPE PATCHES: AN APPLICATION IN NORTH PORTUGAL
}

\author{
SANTOS, M. ${ }^{1} *$ - CABRAL, J.A. \\ ${ }^{I}$ Laboratory of Applied Ecology, CITAB - Centre for the Research and Technology of Agro- \\ Environment and Biological Sciences, \\ University of Trás-os-Montes e Alto Douro, 5000-911, Vila Real, Portugal \\ (phone: +351259350238; fax: +351259350000) \\ *Corresponding author \\ e-mail:mgsantos@utad.pt \\ (Received $8^{\text {th }}$ October 2010; accepted $8^{\text {th }}$ April 2011)
}

\begin{abstract}
A simple methodology was applied with the purpose of understanding the effects of anthropogenic disturbances in the biodiversity of landscape patches, namely by using Soil Surface Dwelling Arthropods as relevant indicators in changing scenarios. The goal of the present paper is to apply and extend the above academic concepts to landscape management, and to demonstrate the potential of a Stochastic Dynamic Methodology in implementing the respective actions. Since many of the ecosystem phenomenological aspects are the result of whole-system properties, the main purpose of the Stochastic Dynamic Methodology is to promote a mechanistic understanding of the holistic ecological processes, based on statistical parameter estimation methods. In this perspective, the proposed protocol is compatible with most activities undertaken by conventional ecological science, i.e., pattern seeking, the ability to explain past and present states, and the ability to predict future states. Additionally, in contexts relating to landscape management, the results of the Stochastic Dynamic Methodology applied to monitoring and restoration activities are intuitive and can be easily communicated to non-experts (ranging from students to resource users and senior policy makers).
\end{abstract}

Keywords: Soil Surface Dwelling Arthropods; Stochastic Dynamic Methodology; Biodiversity Indicators; Landscape patches; Landscape management

\section{Introduction}

The world's landscapes are influenced by a set of anthropogenic pressures that put at risk their sustainability and weaken their ecological functions and societal services (Palmer et al., 2005; Tianhong et al., 2009). This problem has lead to an emphasis for developing accurate assessments of ecosystems status (Rapport et al., 1998; Rapport and Singh, 2006; Giordani et al., 2009). In this scope, the need for rapid, standardized and cost-saving assessment methodologies is crucial, namely to predict how anthropogenic environmental changes will affect the abundance of species, guilds and communities (Andreasen et al., 2001; Gibbons et al., 2009). For conservation and management purposes, the use of appropriate biodiversity indicators may reveal the effect of changes in environmental factors (Jackson et al., 2000; Niemeijer and de Groot, 2008) and provide useful data to characterize composition, structure, and function of complex systems (Müller et al., 2000; Jørgensen, 2008; Doren et al., 2009). Since most environmental impacts are phenomena occurring after a time-lag, early indications of change need to be identified (Bässler et al., 2009).

Arthropods are reported, in many situations, as relevant biodiversity indicators (e.g. Ueahara-Prado et al., 2009). Despite their inconspicuous nature, Soil Surface Dwelling Arthropods (SSDA) are one of the most important components of ecological 
communities in terms of both abundance and diversity (Nakamura et al., 2007). In fact, SSDA are small, diverse, usually sensitive to environmental variability, rapidly respond to disturbance, provide cheap and easy sampling measurements and, therefore, may be assumed to reflect habitat heterogeneity, patch diversity and environmental stress (e.g. Negro et al., 2009; Hoffmam, 2010). If we are able to determine, in a reliable approach, the effects of patch changes in the SSDA abundance and/or composition and their characteristic values in reference areas then we will be able to follow their trends and use then as robust biodiversity indicators (Nakamura et al., 2007).

In many occasions, the indicators trajectory can be followed a priori by using dynamic models for a better comprehension of the stress-response relationships (e.g. Lancelot et al., 2009). In fact, ecological studies have been improved by creating dynamic models that simultaneously attempt to capture the structure and the composition in systems shaped by environmental disturbances (e.g. Chaloupka, 2002; Santos and Cabral, 2004; Santos et al., 2010). The comprehensive use of ecological models has shown a constant and remarkable growth in the last three decades (Williams and Poff, 2006; Jørgensen, 2008). When properly developed and tested, the ecological models must be applied with insight and with regard to their underlying assumptions. These requirements could result in models capable of simulating conditions that are difficult or impossible to understand otherwise. Moreover, the application of ecological models can synthesize the pieces of ecological knowledge, emphasizing the need for a holistic view of a certain environmental problem (Forrester, 1973; Jørgensen, 2001; Schizas and Stamou, 2007; Jørgensen, 2008).

Since many of the ecosystem phenomenological aspects are holistic, whole-system properties, the main vocation of the Stochastic Dynamic Methodology (StDM) is a mechanistic understanding of ecological processes, based on statistical parameter estimation methods (Santos and Cabral, 2004; Cabral et al., 2008; Santos, 2009). The $\mathrm{StDM}$ is a sequential modelling process developed in order to predict the ecological status of systems, from which management strategies can be designed. This recent research is based on the premise that the general patterns of ecological phenomena are emergent indicia of complex ecological processes that do indeed reflect the operation of universal law-like mechanisms (Cabral et al., 2008). In this scope, the StDM was successfully applied in several types of scenarios, such as agro-ecosystems (Santos and Cabral, 2004; Cabral et al., 2007), mountain running waters and reservoirs (Cabecinha et al., 2004; Cabecinha et al., 2007; Cabecinha et al., 2009), estuaries (Silva-Santos et al., 2006; Silva-Santos et al., 2008), wildlife conservation (Santos et al., 2007; Silva et al., 2010), bird survey testing (Santos et al. 2009) fire effects in forest ecosystems (Silva-Santos et al., 2010) and wind farm impacts in mountain ecosystems (Santos et al., 2010).

Therefore, the ultimate objective of the paper was to show, in contexts relating to landscape management, the possibility of using a StDM protocol for predicting changes in the biodiversity associated to patch dynamics, which will be valuable to those engaged in research and teaching landscape ecology.

\section{Materials and methods}

\section{Study site}

The methodology was applied in the campus of the University of Trás-os-Montes e

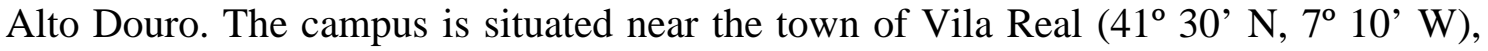


north Portugal (Fig. 1a), in a plateau with an average altitude of 500 meters above the sea-level. The bio-climatologists classify the study area as "mesomediterranean" with precipitation values of $1200 \mathrm{~mm} /$ year and an average annual temperature of $12{ }^{\circ} \mathrm{C}$. The campus mosaic is representative of the region's landscape (Fig. 1 b).

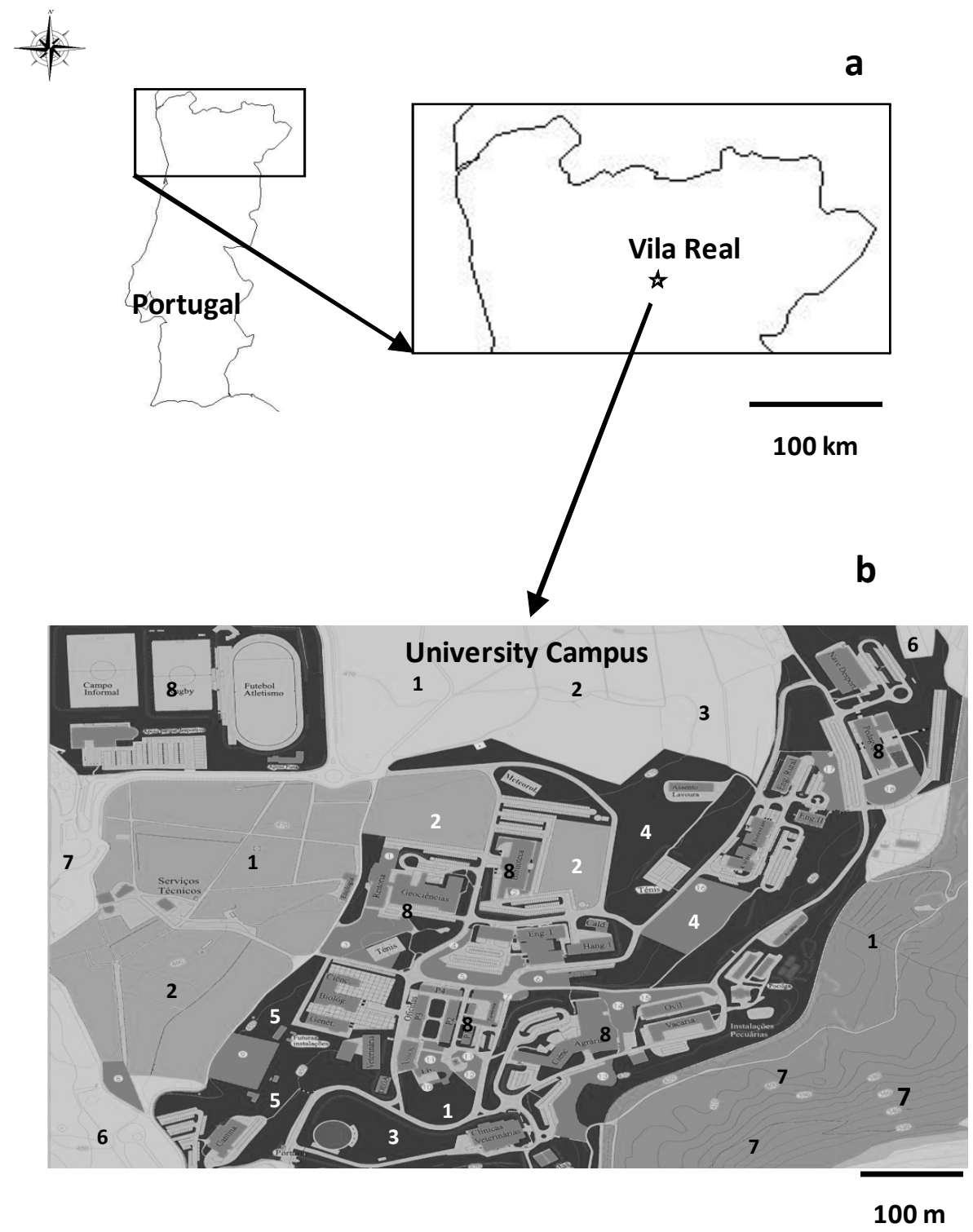

Figure 1. Location of the of study site in (a) North Portugal and (b) a detailed map of the University of "Trás-os-Montes e Alto Douro" Campus: (1) vineyards, (2) cereal fields, (3) olive orchards, (4) woodlands, (5) chestnut plantations, (6) pastures, (7) shrublands (8) social areas not considered for the implementation of the protocol

\section{Data collection}

One hundred and twenty seven circular plots, each one with a radius of 25 meters (to eliminate the factor size and shape of patch), were surveyed during one month (May 2009). Overall, the plots represent the structural heterogeneity of the study area, in terms of the different local characteristics of the main habitats (mosaic), an important 
requirement for the unbiased comprehension of the indicators response in a hypothetical patch. Each plot description and surveys were made in its centre, sited by using a Global Position System device (Magellan GPS $320^{\circledR}$ ) and the respective slope, aspect and topography were recorded.

The vegetation cover was estimated by using visual estimates and reference frames (using crown densitometer) for the trees and shrubs layer and direct measurements (using frame quadrats) for the herbaceous and mosses layer. The vegetation height was measured using a clinometer for the trees and shrubs layer (Suunto 802575) and direct measurements for the herbaceous and mosses layer (using a metric diameter tape).

Soil Surface Dwelling Arthropods (SSDA) were sampled using two pitfall traps of $500 \mathrm{~cm}^{3}$ in each plot (depth $10 \mathrm{~cm}$, mouth diameter $8 \mathrm{~cm}$, bottom diameter $6 \mathrm{~cm}$ ) filled to one third with polyethylene glycol. Trap locations were separated by $5 \mathrm{~m}$ intervals and were removed after seven days. All SSDA specimens were isolated from the debris in the laboratory, stored in $80 \%$ ethyl alcohol, and identified to the Order level using taxonomic keys (Borror et al., 1992) and a binocular microscope (Leica Zoom 2000). All of the specimens were deposited in an insect storage room in the laboratory.

\section{Data analysis}

\section{Determining the taxa responses}

The statistical procedure selected to test for relationships between the biodiversity indicators (SSDA Orders) and the vegetation characteristics was a stepwise multiple regression analysis (Zar, 1996). A step down procedure was used so that the effect of each variable in the presence of all other related variables could be examined first with the least significant variable being removed at every step. The analysis stopped when all the remaining variables had a significant level $\mathrm{P}<0.05$ (Zar, 1996). Although the lack of normality distribution of the dependent variables was not solved by any transformation (Kolmogorov-Smirnov test), the linearity and the homoscedasticity of the residuals were achieved by using logarithmic transformations $\left(X^{\prime}=\log [X+1]\right)$ in each side of the equation, i.e., on both the dependent and independent variables (Zar, 1996). The lack of substantial intercorrelation among independent variables was confirmed by the inspection of the respective tolerance values. The statistical analysis was carried out using the software SYSTAT $8.0^{\circledR}$.

\section{Conceptualisation of the model}

Since the previous statistical procedure was supported on a database which included gradients between the different habitats, over space, the significant partial regression coefficients were assumed as relevant ecological parameters in the dynamic model construction. This is the heart of the philosophy of the StDM. In a holistic perspective, the partial regression coefficients represent the global influence of the environmental variables selected, which are of significant importance on the indicators, namely on several complex ecological processes associated with arthropod taxa abundance and composition (Santos and Cabral, 2004; Santos, 2009). These processes were not included explicitly in the model, but were implicitly related to the state variables (or indicators) under consideration. STELLA 9.0.3. ${ }^{\circledR}$ software was used for the development of the dynamic model. Thereafter, the SSDA were assigned to feeding guilds, based on literature review, and aggregated into trophic groups (predators, 
omnivorous, herbivorous and detritivorous) with the intention of facilitating the perception of the structural and functional changes occurring in the studied landscape.

\section{Model simulations}

The guilds' trends were then simulated using realistic scenarios of plant succession and plant retro-regressive succession associated with possible man-made disturbances (through 20 years, using the year as unit of time) in selected patches of the landscape. The scenarios considered, for academic demonstration and discussion, were: a) a forested patch, affected by a wild fire scenario and the subsequent secondary succession process and b) a patch where cereal crop is substituted by chestnut (Castanea sativa) orchards.

\section{Results}

\section{Effects of the vegetation variables on the selected indicators}

A total of fifteen dependent variables (our arthropod indicators) such as bugs (L Heteroptera, Table 1) and eight independent variables, regarding the habitat characterization (e.g. L Vegetation Height, Table 1) were considered in the multipleregression analysis to search for significant relationships between these components of the study system. Depending on the indicator group, the significant associations with the habitat characteristics were variable. The regression equations and their significance for all the combinations performed are listed in Table 2.

Table 1. Specification of the key variables considered in this study

\begin{tabular}{l|l|l}
\hline Variables & Specification & Model Codes for logarithms (L) \\
\hline Vegetation variables & & \\
Vegetation height & Meters & L Vegetation Height \\
Tree stratum height & Meters & L Tree Height \\
Shrub stratum height & Meters & L Shrubland Height \\
Herb stratum height & Meters & L Herbaceous Height \\
Tree stratum cover & Percentage & L Tree Cover \\
Shrub stratum cover & Percentage & L Shrubland Cover \\
Herb stratum cover & Percentage & L Herbaceous Cover \\
Moss stratum cover & Percentage & L Mosses Cover \\
Arthropod groups & & \\
Acari & Abundance & L Acari \\
Araneida & Abundance & L Araneida \\
Chilopoda & Abundance & L Chilopoda \\
Coleoptera & Abundance & L Coleoptera \\
Collembola & Abundance & L Collembola \\
Diplopoda & Abundance & L Diplopoda \\
Diplura & Abundance & L Diplura \\
Diptera & Abundance & L Diptera \\
Heteroptera & Abundance & L Heteroptera \\
Hymnoptera & Abundance & L Hymnoptera \\
Isoptera & Abundance & L Isoptera \\
Lepidoptera & Abundance & L Lepidoptera \\
Opiliones & Abundance & L Opiliones \\
Orthoptera & Abundance & L Orthoptera \\
Thysanoptera & Abundance & L Thysanoptera \\
\hline
\end{tabular}


Table 2. The regression equations, degrees of freedom (DF), coefficient of determination $\left(R^{2}\right), F$-value and their significance level $(* P<0.05, * * P<0.01$ and $* * * P<0.001)$ for all the combinations selected as significant by the stepwise multiple regression (n.a., not applicable). The specification of all variables' codes is available in Table 1.

\begin{tabular}{l|l|l|l}
\hline Equations & DF & $\mathbf{R}^{2}$ & $\mathbf{F}$ \\
\hline Log Araneida $=0.750-0.186$ Log Vegetation Height & 125 & 0.040 & $5.21^{*}$ \\
\hline $\begin{array}{l}\text { Log Acari }=-0.0844+0.619 \text { Log Shrubland Height }+0,548 \text { Log } \\
\text { Herbaceous Cover }\end{array}$ & 125 & 0.225 & $17.88^{* * *}$ \\
\hline Log Opiliones $=0,0298-0.0336$ Log Vegetation Height & 125 & 0.038 & $4.93^{*}$ \\
\hline Log Chilopoda $=0.0048$ & 125 & n.a. & n.a. \\
\hline Log Diplopoda $=0.0062$ & 125 & n.a. & n.a. \\
\hline $\begin{array}{l}\text { Log Lepidoptera }=0.0125+0.155 \text { Log Herbaceous Cover }-0.236 \log \\
\text { Mosses Cover }\end{array}$ & 125 & 0.089 & $6.01^{* *}$ \\
\hline Log Thysanoptera $=0.0072$ & 125 & n.a. & n.a. \\
\hline $\begin{array}{l}\text { Log Hymenoptera }=0.203+0.407 \text { Log Herbaceous Cover }-0.572 \text { Log } \\
\text { Mosses Cover }+0.175 \text { Log Tree Height }\end{array}$ & 125 & 0.108 & $4.92^{* *}$ \\
\hline Log Diptera $=0.5339$ & 125 & n.a. & n.a. \\
\hline $\begin{array}{l}\text { Log Collembola }=0.936-0.760 \text { Log Tree Height }+0.011 \text { Log Shrubland } \\
\text { Height }+0.836 \log \text { Tree Cover }-0.766 \text { Log Shrubland Cover }\end{array}$ & 125 & 0.212 & $8.16^{* * *}$ \\
\hline $\begin{array}{l}\text { Log Orthoptera }=-0.0120+0,0825 \text { Herbaceous Height } \\
\text { Log Coleoptera }=0.601-0.416 \text { Log Vegetation Height }\end{array}$ & 125 & 0.035 & $4.5^{*}$ \\
\hline $\begin{array}{l}\text { Log Heteroptera }=0.166+0.239 \text { Log Shrubland Height }-0.579 \text { Shrubland } \\
\text { Cover }+0.673 \text { Mosses Cover }\end{array}$ & 125 & 0.193 & $29.59^{* * *}$ \\
\hline Log Diplura $=0.0048$ & 125 & n.a. & n.a. \\
\hline $\begin{array}{l}\text { Log Isoptera }=0.0859-0.0801 \text { Log Vegetation Height }-0.250 \text { Log } \\
\text { Shrubland Cover }+0.443 \text { Log Mosses Cover }\end{array}$ & 125 & 0.106 & $4.83^{* *}$ \\
\hline
\end{tabular}

\section{Construction of the model and equations}

The diagrams of the sub-models presented in the Fig. 2 are based on (a) the relationships detected in the multiple regression analysis (Table 2), (b) the expected succession of the vegetation in this type of patches of north Iberia, highly influenced by anthropogenic disturbances (e.g. Santos et al., 2010), and (c) the SSDA orders aggregation into guilds. The description of the model, equations and source code are shown in Appendixes 1 and 2.

\section{Model simulations}

The scenarios considered, for demonstration purposes, were based on a possible succession of the habitat structure facing the temporal drifts that could occur in a patch of the studied area. The temporal unit chosen was the year, considered acceptable to simulate the changes and the consequent ecological trends of SSDA throughout a period of 20 years (Fig. $2 c$ and $2 d$, total taxa abundance and composition, guilds abundance and composition).

The Fig. $3 a$ and $3 b$ show a scenario where a forest patch is affected by fire in the third year, starting a new succession process: $(3 a)$ the vegetation cover (dominated by the tree cover) is expected to decrease sharply, being afterwards dominated by the herbaceous cover and in the last years by the shrubland cover; $(3 b)$ the vegetation height has the same pattern of the vegetation cover, changing from a tree dominated area to a herbaceous dominated area which allows a gradual shrubland recovery. 


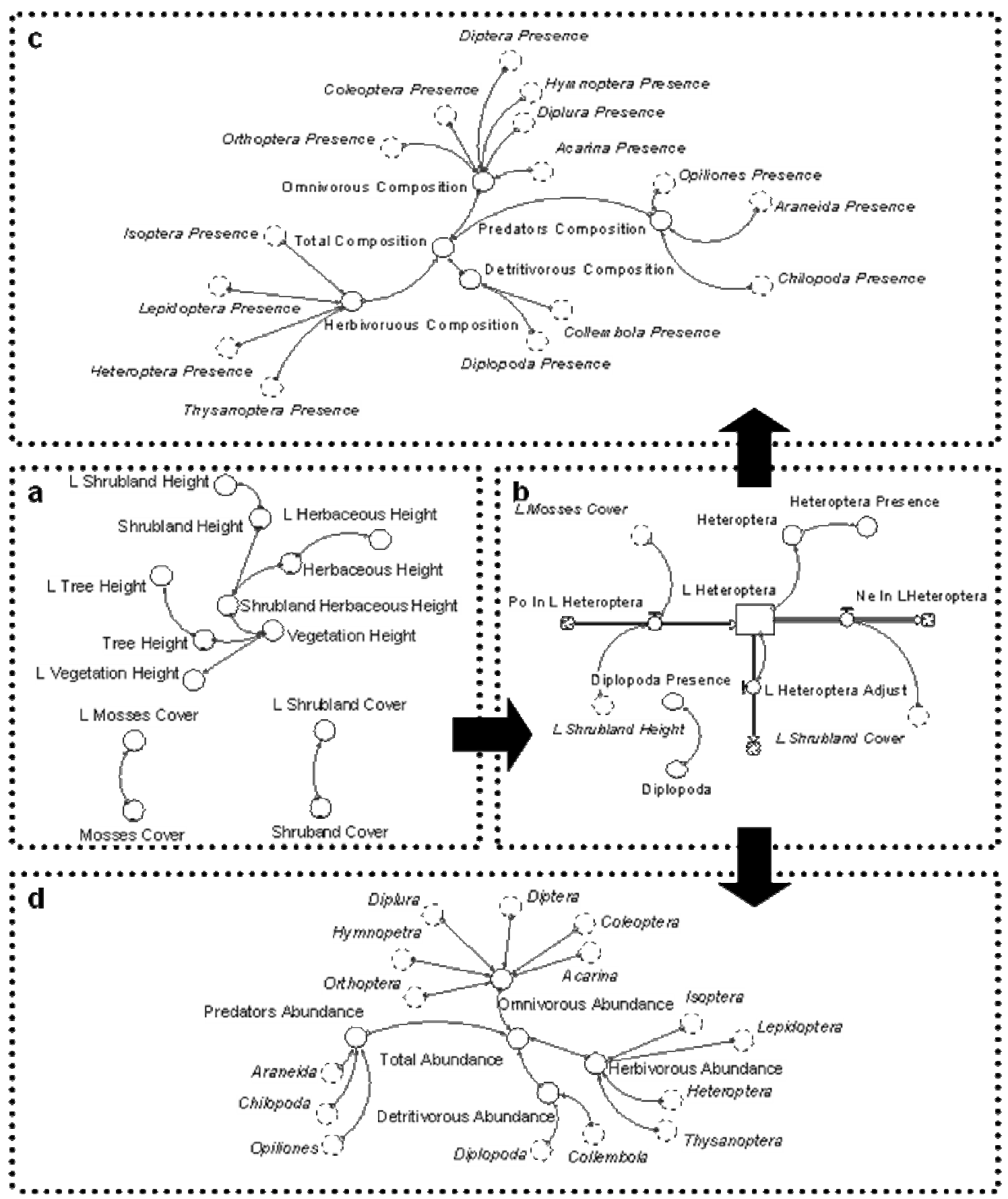

Figure 2. Conceptual diagram of the sub-models used (a) to simulate the vegetation dynamics,

(b) to predict arthropods' dynamics in response to changing vegetation and ( $c$ and $d$ ) to estimate the guilds' dynamics. Rectangles represent state variables; other variables, parameters or constants are small circles; sinks and sources are cloudlike symbols; flows are thick arrows; all the relations between state variables and other variables are fine arrows. As an example, only the variables associated to the Heteroptera and Diplopoda are represented in the sub-

models $a$ and $b$ to illustrate the respective link with the guilds' sub-models $c$ and $d$. The specification of all variable codes is expressed in Table 1 and in the Appendix 1 and Appendix 2 

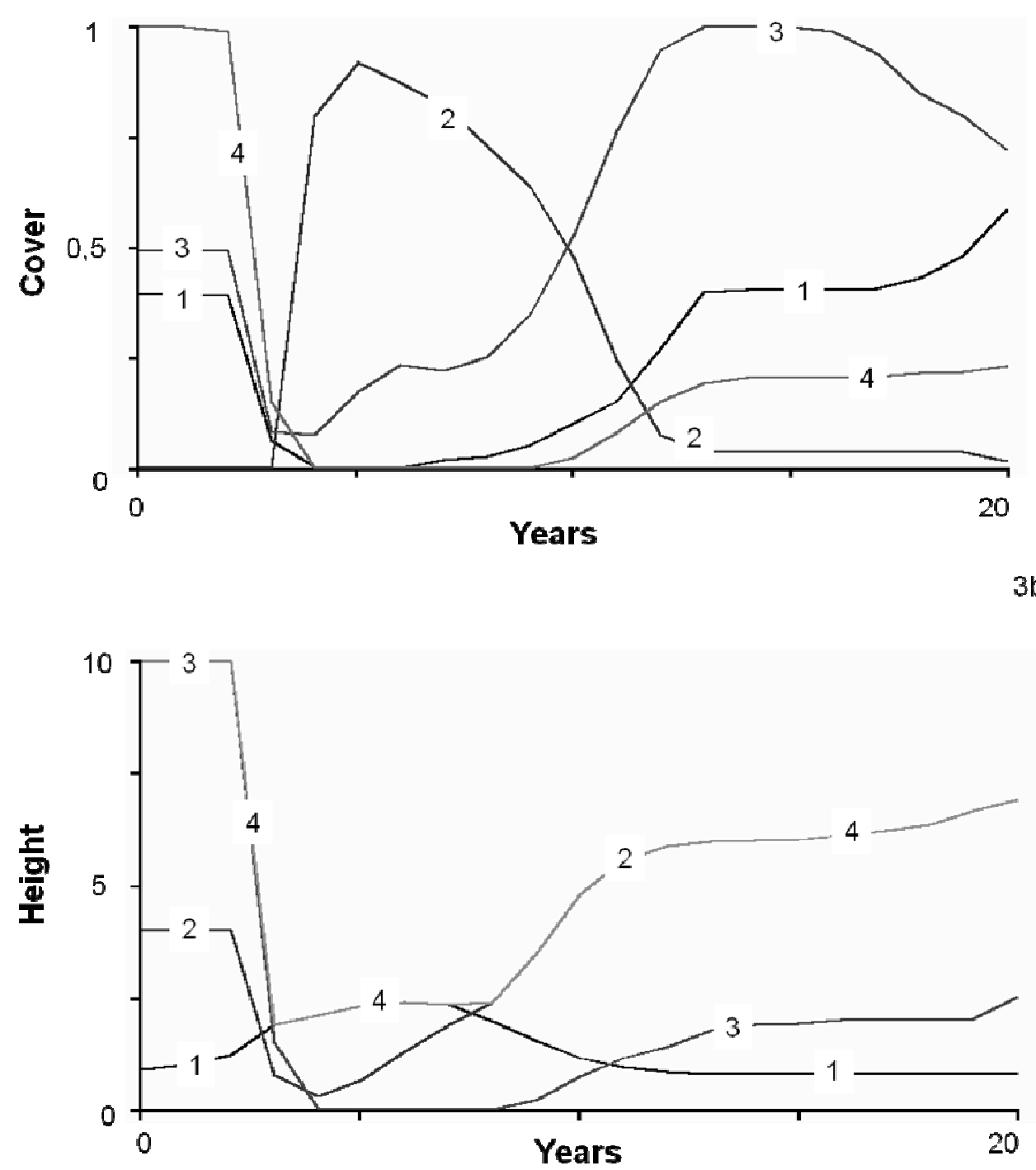

Figure 3. Simulation of a scenario where a forest plot is affected by a fire in the third year and the vegetation re-establishes to a shrubland in the subsequent years. Figure and lines explanation: Fig. 3 a illustrates the changes in cover by stratum (in proportion), (1) Mosses, (2) Herbaceous, (3) Shrub and (4) Tree; Fig. $3 b$ illustrates the changes in height by stratum (in meters), (1) Herbaceous, (2) Shrub, (3) Tree and (4) Vegetation

In response to this scenario the simulations of the SSDA guilds are shown in Fig. $4 a$ and $4 b$. In the Fig. $4 a$ the abundance of SSDA (guilds and total taxa) is influenced (the variations in abundance are dissimilar) by the vegetation structural changes. Even though total taxa and most guilds respond by increasing their abundance in the post-fire (100\%, 500\%, 40\% and 35\%, for Total taxa, Detritivorous, Omnivorous and Predators, respectively) their numbers tend to the pre-fire values as the vegetation structure becomes more complex (approximating pre-fire conditions). The only exception to this increasing trend in post-fire conditions is the Herbivorous guild that clearly reacts with a decline in $35 \%$ in numbers, although shifting to the initial values as the conditions become similar to pre-fire. 

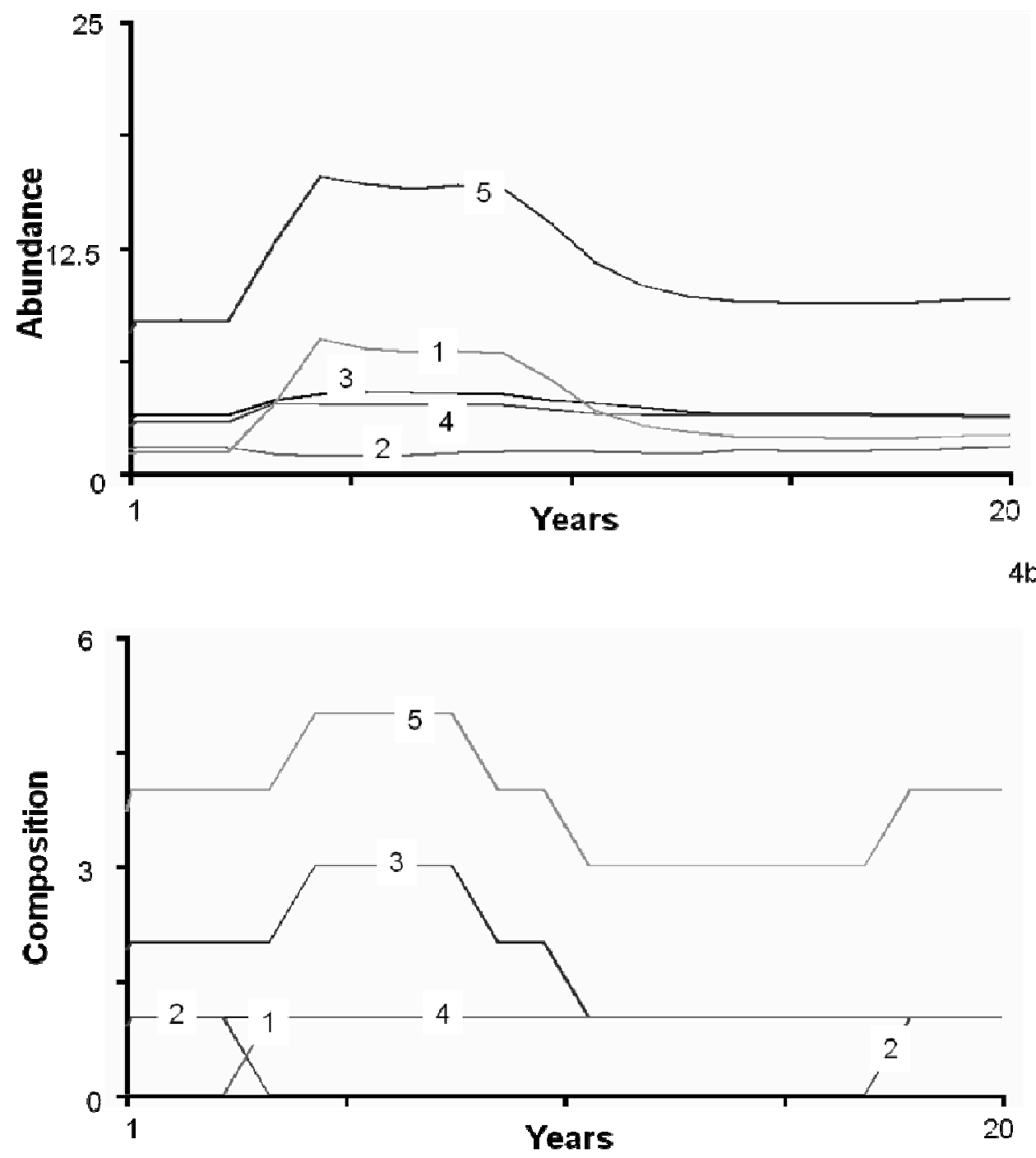

Figure 4. The response of the indicators (arthropods' guilds abundance and composition and total taxa abundance and composition) to the scenario of figure 3. Figures and lines explanation: Fig. 4a illustrates the changes in abundance of the indicators and Fig. $4 b$ shows the changes in the respective composition, (1) Detritivorous, (2) Herbivorous, (3) Omnivorous, (4) Predators and (5) Total taxa

The SSDA guilds' composition (or taxa diversity) varies, namely to post-fire conditions and vegetation recover through divergent and alternate trends (Fig. 4b). In fact, there is an initial increase for Total taxa and Omnivorous (25\% and 50\%, respectively) followed by a regular decline (25\% and 50\%, respectively) (Fig. $4 b$ ). Other taxa have different responses: the Herbivorous react with an initial decrease $(100 \%)$ and a subsequent increase and stabilization, the Predators do not change while the Detritivorous increase (0 to 1) (Fig. $4 b$ ).

The Fig. $5 a$ and $5 b$ illustrate a scenario where a patch of pasture is converted to a Chestnut orchard in the third year: $(5 a)$ the vegetation cover (dominated by the herbaceous cover) is expected to disappear, being afterwards dominated by the cover of the planted small trees; $(5 b)$ the vegetation height has the same pattern as the vegetation 
cover, increasing as a result of the substitution of the herbaceous plants by the trees in a gradient from a herbaceous dominated area to a tree dominated area.

In response to this scenario the simulations of the SSDA guilds are illustrated in Fig. $6 a$ and $6 b$. The Fig. $6 a$ shows that the abundance of most guilds decreases gradually, responding to structural changes in the vegetation $(76 \%, 27 \%, 17 \%, 28 \%$ and $50 \%$ for Detritivorous, Predators, Herbivorous, Omnivorous and Total taxa) although with a small increase in the Predators (15\%) and Omnivorous $(2 \%)$ in the planting period. In this scenario, the taxa composition only changes by a decline in the Omnivorous (33\%) and Total taxa $(20 \%)$.

\section{Discussion}

The obtained results are in conformity with several studies that tried to identify the disturbance effects on the local communities by using indicator taxa approaches (e.g. Billeter et al., 2008; Gibbons et al., 2009; Sattler et al., 2010). In fact, the response of arthropods to vegetation changes is variable, depending on the type of change, ecosystem and group studied (e.g. Antunes et al., 2008; Hoffmam et al., 2010). The apparent resilience of some guilds may show taxa adaptation to disturbances and low diversity, in agreement to the results obtained in other studies in similar conditions (e.g. Bengtsson, 2002; Moretti et al., 2006; Slocum and Mendelssohn, 2008). On the other hand the idea that the diversity increases as succession proceeds (Martinko et al., 2006) is not corroborated by our simulation results. The obtained results show that the initial phases of succession (dominated by herbaceous layer) seem to contain the most abundant and diverse SSDA communities. Previous studies have demonstrated that coexisting taxa partition their resources and/or that the compositional similarity between communities is determined by environmental factors, lending support to the nicheassembly model. However, no attempt has been made to investigate whether the amount of resources that reflects relative niche space controls relative taxa abundance and composition in communities (Schweiger et al., 2005). Here, we demonstrate that the relative abundance and composition in patches is significantly related to the relative structure of the vegetation (biomass). Since the abundance and composition of the SSDA guilds is determined by the habitat structure, the simulations allow a better perception of the biodiversity consequences related to vegetation structural changes. Therefore, the proposed methodology should be considered as a complementary tool in landscape management, by using indicators within the "data space" of the environmental gradients monitored in particular systems, such as our case-study in anthropogenic habitats of North Portugal. 

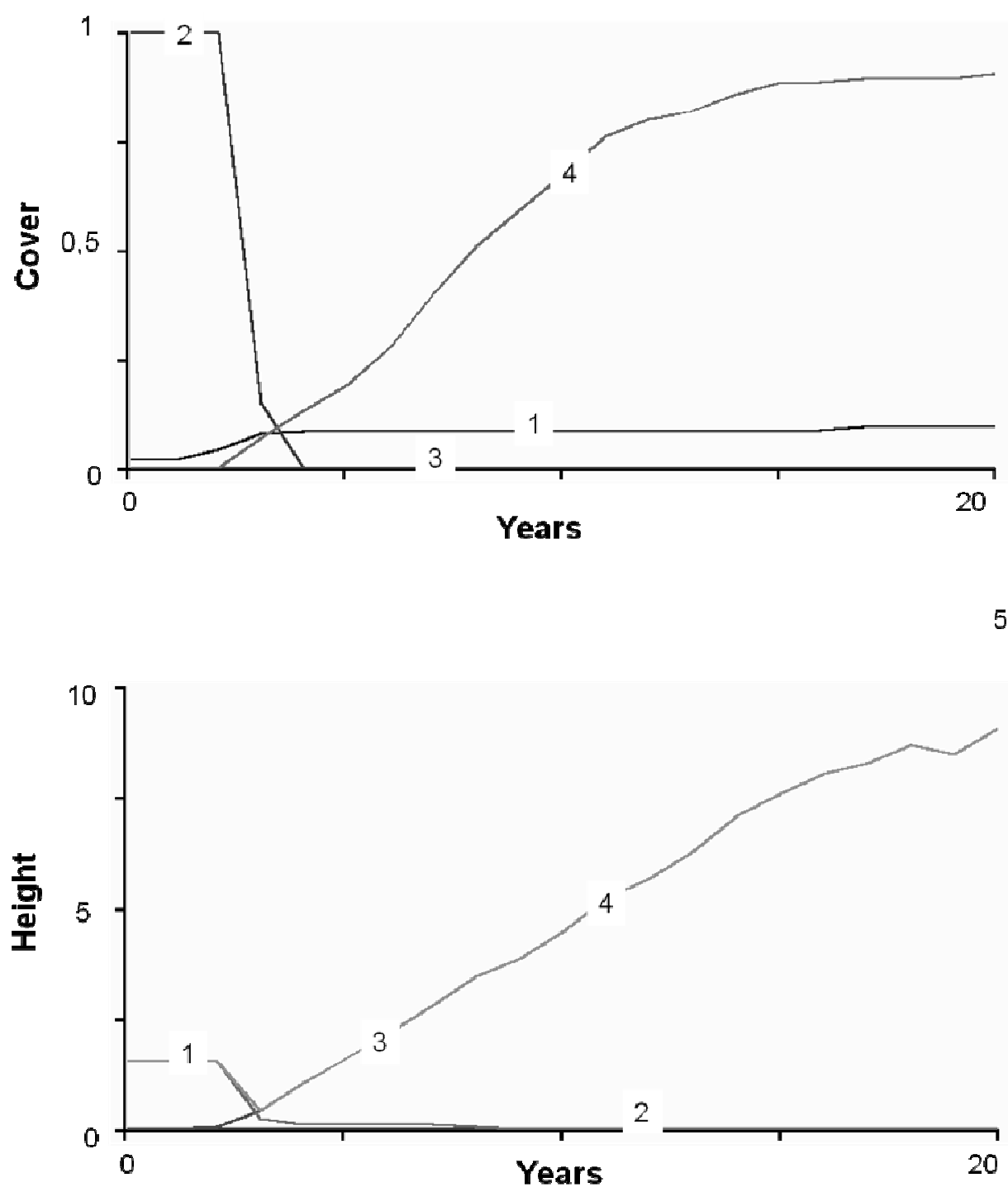

Figure 5. Simulation of a scenario where a pasture is substituted in the third year by a Chestnut orchard that evolves in the subsequent years. Figure and lines explanation: Fig. 5a illustrates the changes in cover by stratum (in proportion), (1) Mosses, (2) Herbaceous, (3) Shrub and (4)

Tree; Fig. $5 b$ illustrates the changes in height by stratum (in meters), (1) Herbaceous, (2) Shrub, (3) Tree and (4) Vegetation 


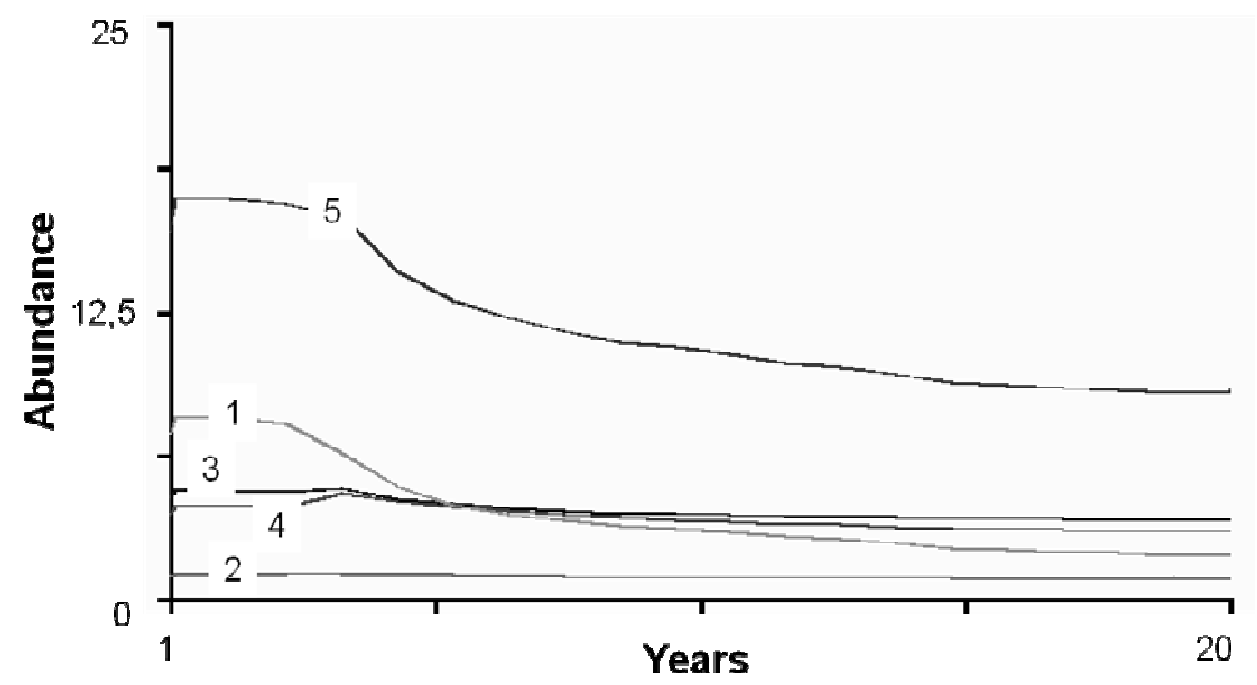

$6 \mathrm{~b}$

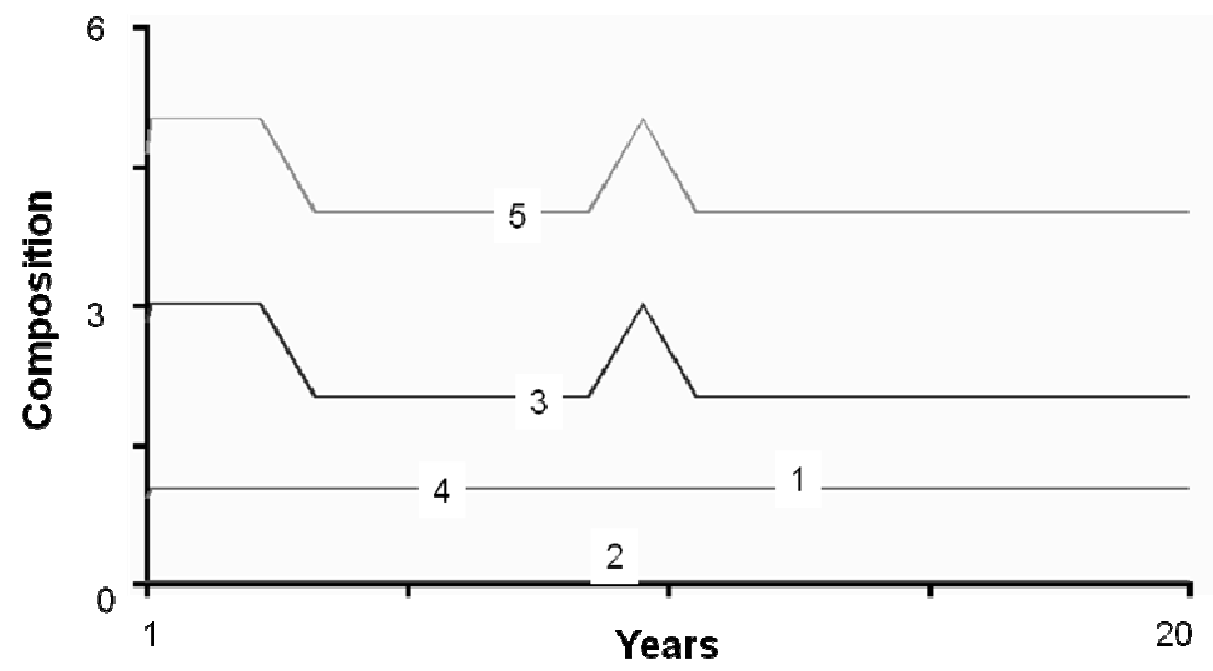

Figure 6. The response of the indicators (arthropods' guilds abundance and composition and total taxa abundance and composition) to the scenario of figure 5. Figures and lines explanation: Fig. 6a illustrates the changes in abundance of the indicators and Fig. $6 \mathrm{~b}$ shows the changes in the respective composition, (1) Detritivorous, (2) Herbivorous, (3) Omnivorous, (4) Predators and (5) Total taxa

As with any ecological modelling procedure (Jørgensen, 2001), the complexity of a StDM model is determined by the problem, the choice of the key-components in the studied ecosystem and the available data. One of the most important requirements identified in the StDM is linked to the quality of the data-base, crucial for the performance of the model outputs. The central requirements of the StDM data set recorded includes: (1) a large amount of data, because in the regression analysis the slope is chosen so that the sum-of-squares distance between each data point and the fitted line is minimised (Sokal and Rolf, 1995) and (2) the pertinent spatial and temporal 
gradients of changes, in order to represent the relevant attributes of the scenarios selected and to allow realistic simulations of the indicator's responses, given that in regression analysis the limits of the $\mathrm{Y}$ prediction are imposed by the extreme points of the fitted line (Waite, 2000; Steele et al., 2005). Other criteria from stepwise regression, such as Akaike selection criteria (AIC) (Akaike, 1974) and Mallows Cp (Mallows, 1973) could be used for choosing the most parsimony model to be incorporated in a StDM approach.

Models produced in the form of rules, based on machine learning approaches, are transparent and can be easily understood (Mendonza and Prabhu, 2005). The structure of such models should be straightforwardly interpretable in order to allow the incorporation of pertinent qualitative data before the simulations (Dale and Beyler, 2001; Lancelot et al., 2009). The StDM exhibits these structural qualities but provides also simple, suitable and intuitive outputs, easily interpreted by non-experts (ranging from students to senior policy makers). Another goal when developing methodologies for assessing changes in the ecological integrity of systems is the feasibility of application and extent to which the results can be applied in other areas, taxa and problems (Andreasen et al., 2001; Duelli and Obrist, 2003). In fact, despite the limitations inherent to an academic demonstration, the protocol proposed is expeditious and easily applicable to other types of databases dealing with ecosystems affected by gradients of changes (Santos, 2009). Although conceptually simple, our StDM protocol captures the complexity of some holistic ecological trends, including realistic temporal and spatial gradients of environmental characteristics, which allowed the simulation of structural changes when habitat and environmental conditions are substantially changing due to anthropogenic-induced alterations (Cabral et al., 2008). Since the biodiversity of the patch communities can be only partly assessed by SSDA indicators diversity and composition, this approach also provides a useful starting point, allowing the precise development of more complicated models, with introduction of other indicators, interactions and interferences (such as the trophic relationships) with precise applicability conditions.

The ultimate goal is to produce simulation models that allow the creation of landscape dynamics from changes is patches, basis of spatially explicit biodiversity assessments (Muzy et al., 2005). Therefore, we believe that our approach will provide the development of techniques in the scope of landscape ecology by creating expeditious interfaces with Geographic Information Systems, which will make the methodology more instructive and credible to decision makers and environmental managers (Costanza, 1992; Santos and Cabral, 2004).

Acknowledgements. The authors are indebt to the colleagues and students from the University of Trásos-Montes e Alto Douro who assisted in field and laboratory, making this work possible. 


\section{REFERENCES}

[1] Akaike, H. (1974): A new look at the statistical model identification. - IEEE Transactions in Automatatic Control 19: 716-723.

[2] Andreasen, J.K., O'Neill, R.V., Noss, R., Slosser, N.C. (2001): Considerations for the development of a terrestrial index of ecological integrity. - Ecological Indicators 1: 2135 .

[3] Antunes, S.C., Pereira, R., Sousa, J.P., Santos, M.C., Gonçalves, F. (2008): Spatial and temporal distribution of litter arthropods in different vegetation covers of Porto Santo Island (Madeira Archipelago, Portugal). - European Journal of Soil Biology 44: 45-56.

[4] Bässler, C., Müller, J., Hothorn, T., Kneib, T., Badeck, F., Dziock, F. (2009): Estimation of the extinction risk for high-montane species as a consequence of global warming and assessment of their suitability as cross-taxon indicators. - Ecological Indicators 10: 341352.

[5] Bengtsson, J. (2002): Disturbance and resilience in soil animal communities. - European Journal of Soil Biology 38: 119-125.

[6] Billeter, R., Liira, J., Bailey, D., Bugter, R., Arens, P., Augenstein, I., Aviron, S., Baudry, J., Bucacek, R., Burel, F., Cerny M., De Blust, G., De Cock, R., Diekötter, T., Dietz, H., Dirksen, J., Dormann, C., Durka, W., Frenzel, M., Hamersky, R., Hendrickx, F., Herzog, F., Klotz, S., Koolstra, B., Lausch, A., Le Couer, D., Maelfait, J.P., Opdam, P., Roubalova, M., Schermann, A., Schermann, N., Schmidt, T., Schweiger, O., Smulders, M.J.M., Speelmans, M., Simova, P., Verboom, J., van Wingerden, W.K.R.E., Zobel, M., Edwards, P.J. (2008): Indicators for biodiversity in agricultural landscapes: a panEuropean study. - Journal of Applied Ecology 45: 1141-1150.

[7] Borror, D.J., Triplehorn, C.A., Johonson, N.F. (1992): An introduction to the study of insects. - Saunders College Publishing, Florida.

[8] Cabecinha, E., Cortes, R., Cabral, J.A. (2004): Performance of a stochastic-dynamic modelling methodology for running waters ecological assessment. - Ecological Modelling 175: 303-317.

[9] Cabecinha, E., Pardal, M.A., Cortes, R., Cabral, J.A. (2009): A Stochastic Dynamic Methodology (StDM) for reservoir's water quality management: validation of a multiscale approach in a south European basin (Douro, Portugal). - Ecological Indicators 9: 329-345.

[10] Cabecinha, E., Silva-Santos, P., Cortes, R., Cabral, J.A. (2007): Applying a stochasticdynamic methodology (StDM) to facilitate ecological monitoring of running waters, using selected trophic and taxonomic metrics as state variables. - Ecological Modelling 207: 109-127.

[11] Cabral, J.A., Cabecinha, E., Santos, M., Travassos, P., Silva-Santos, P. (2008): Simulating the ecological status of changed ecosystems by holistic applications of a new Stochastic Dynamic Methodology (StDM). - In: Alonso, M.S. and Rubio, I.,M. (ed), Ecological Management, New Research. NovaScience Publishers, New York, pp. 123141

[12] Cabral, J.A., Rocha, A., Santos, M., Crespí, A.L. (2007): A stochastic dynamic methodology (SDM) to facilitate handling simple bird indicators in the scope of the agrienvironmental measures problematics. - Ecological Indicators 7: 34-47.

[13] Chaloupka, M. (2002) Stochastic simulation modelling of southern Great Barrier Reef green turtle population dynamics. - Ecological Modelling 148: 79-109.

[14] Costanza, R. (1992) Toward an operational definition of ecosystem health. - In: Costanza, R., Norton, B., Haskell, B. (ed), Ecosystem Health: New Goals for Environmental Management. Island Press, Washington DC. 
[15] Dale, V.H., Beyeler, S.C. (2001): Challenges in the development and use of ecological indicators. - Ecological Indicators 1: 3-10.

[16] Doren, R.F., Trexler, J.C., Gottlieb, A.D., Harwell, M.C. (2009): Ecological indicators for system-wide assessment of the greater everglades ecosystem restoration program. Ecological Indicators 9: S2-S16.

[17] Duelli, P., Obrist, M.K. (2003): Biodiversity indicators: the choice of values and measures. - Agriculture Ecosystems \& Environment 98: 87-98.

[18] Forrester, J.W. (1973): World Dynamics (2 ed.). - Pegasus Communications, Waltham.

[19] Gibbons, P., Brigs, S.V., Ayers, D., Seddon, J., Doyle, S., Cosier, P., McHelhinny, C., Pelly, V., Roberts, K. (2009): An operational method to assess impacts of land clearing on terrestrial biodiversity. - Ecological Indicators 9: 26-40.

[20] Giordani, G., Zaldívar, J.M., Viaroli, P. (2009): Simple tools for assessing water quality and trophic status in transitional water ecosystems. - Ecological Indicators 9: 982-991.

[21] Hoffmam, B.D. (2010): Using ants for rangeland monitoring: Global patterns in the responses of ant communities to grazing. - Ecological Indicators 10: 105-111.

[22] Jackson, L.E., Kurtz, J.C., Fisher, W.S. (2000): Evaluation Guidelines for Ecological Indicators. - Environmental Protection Agency, Washington, DC. Report No. EPA/620/R-99/005.

[23] Jørgensen, S.E. (2001): Fundamentals of Ecological Modelling (3rd Edition). - Elsevier, Amsterdam.

[24] Jørgensen, S.E. (2008): Overview of the model types available for development of ecological models. - Ecological Modelling 215: 3-9.

[25] Lancelot, C., Rousseau, V., Gyphens, N. (2009): Ecologically based indicators for Phaeocystis disturbance in eutrophied Belgian coastal waters (Southern North Sea) based on field observations and ecological modelling. - Journal of Sea Research 61: 44-49.

[26] Mallows, C.L. (1973): Some comments on Cp. - Technometrics 15: 661-675.

[27] Martinko, E.A., Hagen, R.H., Griffith, J.R. (2006): Successional change in the insect community of a fragmented landscape. - Landscape Ecology 21: 711-721.

[28] Mendonza, G.A., Prabhu, R. (2005): Combining participatory modeling and multi-criteria analysis for community based forest management. - Forest Ecology and Management 207: 145-156.

[29] Moretti, M., Deulli, P., Obrist, M.K. (2006): Biodiversity and resilience of arthropod communities after fire disturbance in temperate forests. - Oecologia 146: 312-327.

[30] Müller, F., Hoffmann-Kroll, R., Wiggering, H. (2000): Indicating ecosystem integrity theoretical concepts and environmental requirements. - Ecological Modelling 130: 12-23.

[31] Muzy, A., Innocenti, E., Aïelo, A., Santucci, J., Santonni, P., Hill, D.R.C. (2005): Modelling and simulation of ecological propagation processes: application to fire spread. - Environmetal Modelling Software 20: 827-842.

[32] Nakamura, A., Caterral, C.P., House, A.P.N., Kitching, R.L., Burwell, C.J. (2007): The use of ants and other soil and litter arthropods as bio-indicators of the impacts of rainforest clearing and subsequent land use. - Journal of Insect Conservation 11: 177186.

[33] Negro, M., Isaia, M., Palestrini, C., Rolando, A. (2009): The impact of forest ski-pistes on diversity of ground-dwelling arthropods and small mammals in the Alps. Biodiversity Conservation 18: 2799-2821.

[34] Niemeijer, D., Groot, R.S. (2008): A conceptual framework for selecting environmental indicator sets. - Ecological Indicators 8: 14-25.

[35] Palmer, M.A., Bernhardt, E.S., Chornesky, E.A., Collins, S.L., Dobson, A.P. (2005): Ecological science and sustainability for the 21st century. - Frontiers in Ecology and the Environment 3: 4-11.

[36] Rapport, D.J., Gaudet, C., Karr, J.R., Baron, J.S., Bohlen, C., Jackson, W., Jones, B., Naiman, R.J., Norton, B., Pollock, M.M. (1998): Evaluating landscape health: Integrating societal goals and biophysical process. - Journal of Environmental Management 53: 1-15. 
[37] Rapport, D.J., Singh, A. (2006): An eco-heath based framework for state of environment reporting. - Ecological Indicators 6: 409-428.

[38] Santos, M., Bastos, R., Travassos, P., Bessa, R., Repas, M., Cabral, J.A. (2010): Predicting the trends of vertebrate species richness as a response to wind farms installation in mountain ecosystems of Northwest Portugal. - Ecological Indicators 10: 192-205.

[39] Santos, M., Cabral, J.A. (2004): Development of a stochastic dynamic model for ecological indicators prediction in changed Mediterranean agroecosytems of northeastern Portugal. - Ecological Indicators 3: 285-303.

[40] Santos, M., Travassos, P., Repas, M., Cabral, J.A. (2009): Modelling the performance of bird surveys in non-standard weather conditions: General applications with special reference to mountain ecosystems. - Ecological Indicators 9: 41-51.

[41] Santos, M., Vaz, C., Travassos, P., Cabral, J.A. (2007): Simulating the impact of socioeconomic trends on threatened Iberian wolf populations Canis lupus signatus in northeastern Portugal. - Ecological Indicators 7: 649-664.

[42] Santos, M. (2009): Simplifying complexity: applications of stochastic-dynamic methodology in terrestrial ecology. PhD thesis. - University of Trás-os-Montes e Alto Douro, Vila Real, Portugal.

[43] Sattler, T., Duelli, P., Obrist, M.K., Arletazz, R., Moretti, M. (2010): Response of arthropods species richness and functional groups to urban habitat structure and management. - Landscape Ecology 25: 941-954.

[44] Schizas, D., Stamou, G. (2007): What ecosystems really are Physicochemical or biological entities? - Ecological Modelling 200: 178-182.

[45] Schweiger, O., Maelfait, J.P., Van Windergen, W., Hendrickx, F., Billeter, R., Speelmans, M., Augenstein, I., Aukema, B., Aviron, S., Bailey, D., Bukacek, R., Burel, F., Diekötter, T., Dirksen, J., Frenzel, M., Herzog, F., Liira, J., Roubalova, M., Bugter, R. (2005): Quantifying the impact of environmental factors of arthropod communities in agricultural landscapes across organizational levels and spatial scales. - Journal of Applied Ecology 42: 1129-1139.

[46] Silva, J.P., Santos, M., Queirós, L., Leitão, D., Moreira, F., Pinto, M., Leqoc, M., Cabral, J.A. (2010): Estimating the influence of overhead transmission power lines and landscape context on the density of little bustard Tetrax tetrax breeding populations. - Ecological Modelling 221: 1954-1963.

[47] Silva-Santos, P., Pardal, M.A., Lopes, R.J., Murias, T., Cabral, J.A. (2006): A stochastic dynamic methodology (SDM) to the modelling of trophic interactions, with a focus on estuarine eutrophication scenarios. - Ecological Indicators 6: 394-408.

[48] Silva-Santos, P., Pardal, M.A., Lopes, R.J., Murias, T., Cabral, J.A. (2008): Testing the Stochastic Dynamic Methodology (StDM) as a management tool in a shallow temperate estuary of south Europe (Mondego, Portugal). - Ecological Modelling 210: 377-402.

[49] Silva-Santos, P., Valentim, H., Luís, A., Queirós, L., Travassos, P., Cabral, J.A. (2010) A Stochastic Dynamic Methodology (StDM) to simulate the effects of fire on vegetation and bird communities in Pinus pinaster stands. - Ecological Indicators 10: 206-211.

[50] Slocum, M.G., Mendelssohn, I.A.( 2008): Use of experimental disturbances to assess resilience along a known stress gradient. - Ecological Indicators 8: 181-190.

[51] Sokal, R.R., Rohlf, F.J. (1995): Biometry, $3^{\text {rd }}$ ed. - W.H. Freeman and Company, New York.

[52] Steele, B.M., Reedy, S.K., Nemani, R.R. (2005): A regression strategy for analyzing environmental data generated by spatio-temporal processes. - Ecological Modelling 181: 93-108.

[53] Tianhong, L., Wenkai, L., Zhenghan, Q. (2009): Variations in ecosystem service value in response to land use changes in Shenzhen. - Ecological Economics (in press).

[54] Ueahara-Prado, M., Fernandes, J.O., Bello, A.Y., Machado, G., Santos, A.J., Vaz-deMello, F.Z., Freitas, A.V.L. (2009): Selecting terrestrial arthropods as indicators of small- 
scale disturbance: A first approach in the Brazilian Atlantic Forest. - Biological Conservation 142: 1220-1228.

[55] Waite, S. (2000): Statistical Ecology in Pratice. A Guide to Analysing Environmental and Ecological Field Data. - Pearson Education, Harlow, England.

[56] Williams, J.B., Poff, N.L. (2006): Informatics software for the ecologist's toolbox: A basic example. - Ecological Informatics: 325-329.

[57] Zar, J.H. (1996): Biostatistical Analysis, $3^{\text {rd }}$ ed. - Prentice-Hall International Inc., Englewood Cliffs, New Jersey. 


\section{Appendix 1}

The Fig. $2 a$ shows part of the sub-model diagram that intends to predict the vegetation succession in different deterministic ecological circumstances (only the vegetation characteristics related to Fig. $2 b$ taxon are exposed). Considering that the forecast of vegetation succession highly depends on local characteristics (Santos et al 2010) and for an easier construction of the model, the dynamics of vegetation cover and height (e.g. Shrubland Cover, Shrubland Height) were introduced in the model as table functions (Fig. 2a, Appendix 2 -Table functions), based on the average values for each type of vegetation of the database. The vegetation variables were logarithm transformed for a compatible integration in the balances of the state variables (Fig. $2 a$ and Fig. 2b, Appendix 2 - Associated variables). This transformation (e.g. L Shrubland Cover) was incorporated because the data required for the state variables balances should have the same units used to obtain the partial regression coefficients, assumed as holistic ecological parameters (see Methods). Therefore, only logarithms of the environmental variables are acceptable in the inflows and outflows of the state variables (Fig. $2 b$ and Appendix 2 - Difference equations and Process equations). In Fig. 2b, the sub-model diagram attempts to predict the response of each taxon to the changes that take place in the selected plot (the figure only shows Heteroptera as an example, for other taxon details see Appendix 2). The independent variables were the logarithms of the vegetation characteristics considered (e.g. L Shrubland Cover) (Fig. 2a, Appendix 2 Associated variables) and the selected state variables were the logarithms of the arthropod dependent variables (e.g. L Heteroptera) (Fig. 2b, Table 1). The initial values for these state variables were assumed to be zero (our initial situation in t0) (Appendix 2, Process equations). Later, for simulations representation, the initial value was discarded, since only in $\mathrm{t} 1$ (the first point of the simulation) it was possible to take into account the influences of the vegetation on the estimates. The processes that affect the state variables are described by difference equations (Appendix 2, Difference equations). The inflows (e.g. Po In L Heteroptera) affecting the state variables (e.g. L Heteroptera) were based on positive constants and all positive partial coefficients resulting from the previous multiple regression analysis (Table 1, Fig. 2b, Appendix 2 - Difference and Process equations). On the other hand all the state variables were affected also by outflows (e.g. Ne In L Heteroptera) related to the negative constants and partial regression coefficients influences (Table 1, Fig. 2, Appendix 2 - Difference and Process equations). Although the output for each taxon simulated is composed of a given value per time unit, the respective state variable could have a cumulating behaviour over time in response to changes in the vegetation conditions. Thus, to avoid this, an additional outflow adjustment was incorporated in each state variable (e.g. L Heteroptera Adjust). These outflow adjustments aimed to empty the state variables in each time step, by a "flushing cistern" mechanism, before beginning the next step with new environmental influences (Fig. $2 b$ and Appendix 2 - Difference and Process equations). For process compatibilities and a more realistic comprehension of the model simulations, some conversions were introduced, denominated associated variables (Fig. $2 b$ and Appendix 2 - Associated variables). Regarding the selected taxon, these conversions were obtained through an inverse transformation (anti-logarithmic), which transforms logarithms into the original measurement units (e.g. Heteroptera). Therefore, the model is prepared to accept and transform real data from the variables and to convert logarithmic outputs 
from specific estimation back into the original units. All taxa whose results were indifferent to the independent variables used in the multiple regression analysis (Table 2) were introduced in the model in averaged values (e.g. Diplopoda) and the limit values for their variation are determined in accordance with realistic ranges, such as the respective standard error (Fig. 2b). These limits imposed maximum and minimum values for each stochastic variable, included in the model as random functions (Fig. 2 and Appendix 2 - Stochastic variables). In order to transform taxon abundance into a binomial presence/absence register (e.g. Heteroptera Presence), a logical equation was inserted (Fig. 2 and Appendix 2 - Other variables). In Figs. $2 c$ and $2 d$ the sub-model diagrams aims are to forecast the response of the macro indicators, the SSDA guilds, to the structural changes occurring in the vegetation. The indicators selected were: the SSDA guilds composition (Fig. 2c, number of taxa) (e.g. Herbivorous Composition) and the SSDA guilds abundance (Fig. 2d, number of individuals) (e.g. Herbivorous Abundance). Additionally, the contributions of these groups were considered for the total SSDA abundance and composition estimates (Total Abundance and Total Composition). These variables result from simple mathematical operations between the previous explained associated, stochastic and other variables, called composed variables (Figs. $2 c$ and $2 d$, Appendix 2 - Composed variables). 


\section{Appendix 2}

Mathematical equations used in Stella for the relationships between indicator estimates and the vegetation characteristics. The specification of variable codes is expressed in Table 1.

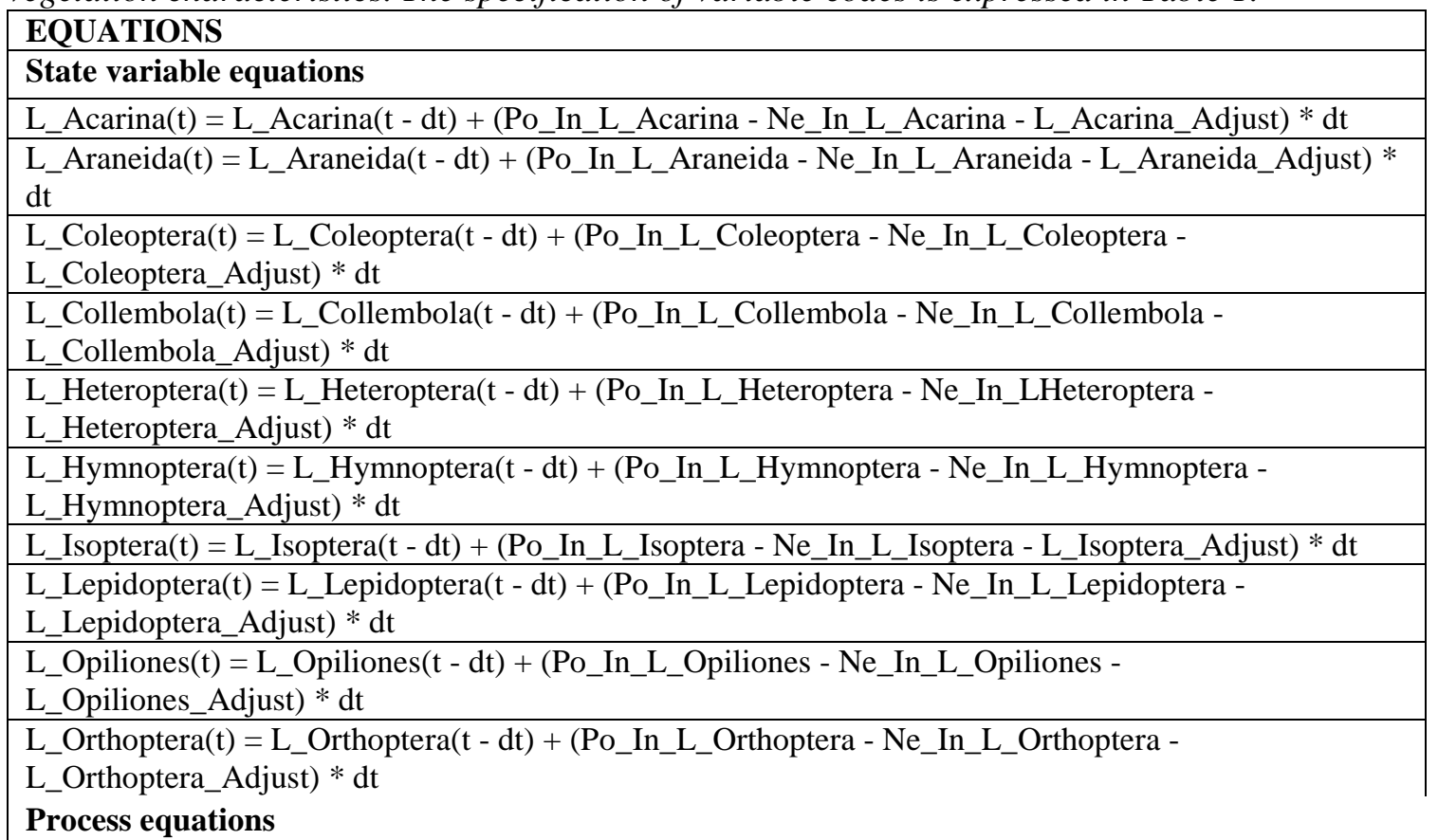

(a) INIT L_Acarina $=0$

Po_In_L_Acarina $=0.619 *$ L_Shrubland_Cover $+0.548 *$ L_Herbaceous_Cover

$\mathrm{Ne}$ In_L_Acarina $=0.085$

L_Acarina_Adjust $=$ L_Acarina

(b) INIT L_Araneida $=0$

Po_In_L_Araneida $=0.749$

Ne_In_L_Araneida $=0.185 *$ L_Vegetation_Height

L_Araneida_Adjust $=$ L_Araneida

(c) INIT L_Coleoptera $=0$

Po_In_L_Coleoptera $=0.601$

Ne_In_L_Coleoptera $=0.416 *$ L_Vegetation_Height

L_Coleoptera_Adjust $=$ L_Coleoptera

(d) INIT L_Collembola $=0$

Po_In_L_Collembola $=0.936+0.011 *$ L_Shrubland_Height $+0.836 *$ L_Tree_Cover

Ne_In_L_Collembola $=0.760 *$ L_Tree_Height $+0.766 *$ L_Shrubland_Cover

L_Collembola_Adjust $=$ L_Collembola

(e) INIT L_Heteroptera $=0$

Po_In_L_Heteroptera $=0.166+0.239 *$ L_Shrubland_Height $+0.673 *$ L_Mosses_Cover

Ne_In_LHeteroptera $=0.579 *$ L_Shrubland_Cover

L_Heteroptera_Adjust $=$ L_Heteroptera

(f) INIT L_Hymnoptera $=0$

Po_In_L_Hymnoptera $=0.203+0.407 *$ L_Herbaceous_Cover $+0.175 *$ L_Tree_Height

Ne_In_L_Hymnoptera $=0.572 *$ L_Mosses_Cover

L_Hymnoptera_Adjust $=$ L_Hymnoptera

(g) INIT L_Isoptera $=0$

Po_In_L_Isoptera $=0.0859+0.443 *$ L_Mosses_Cover

Ne_In_L_Isoptera $=0.0801 *$ L_Vegetation_Height $+0.250 *$ L_Shrubland_Cover

L_Isoptera_Adjust $=$ L_Isoptera

(h) INIT L_Lepidoptera $=0$ 


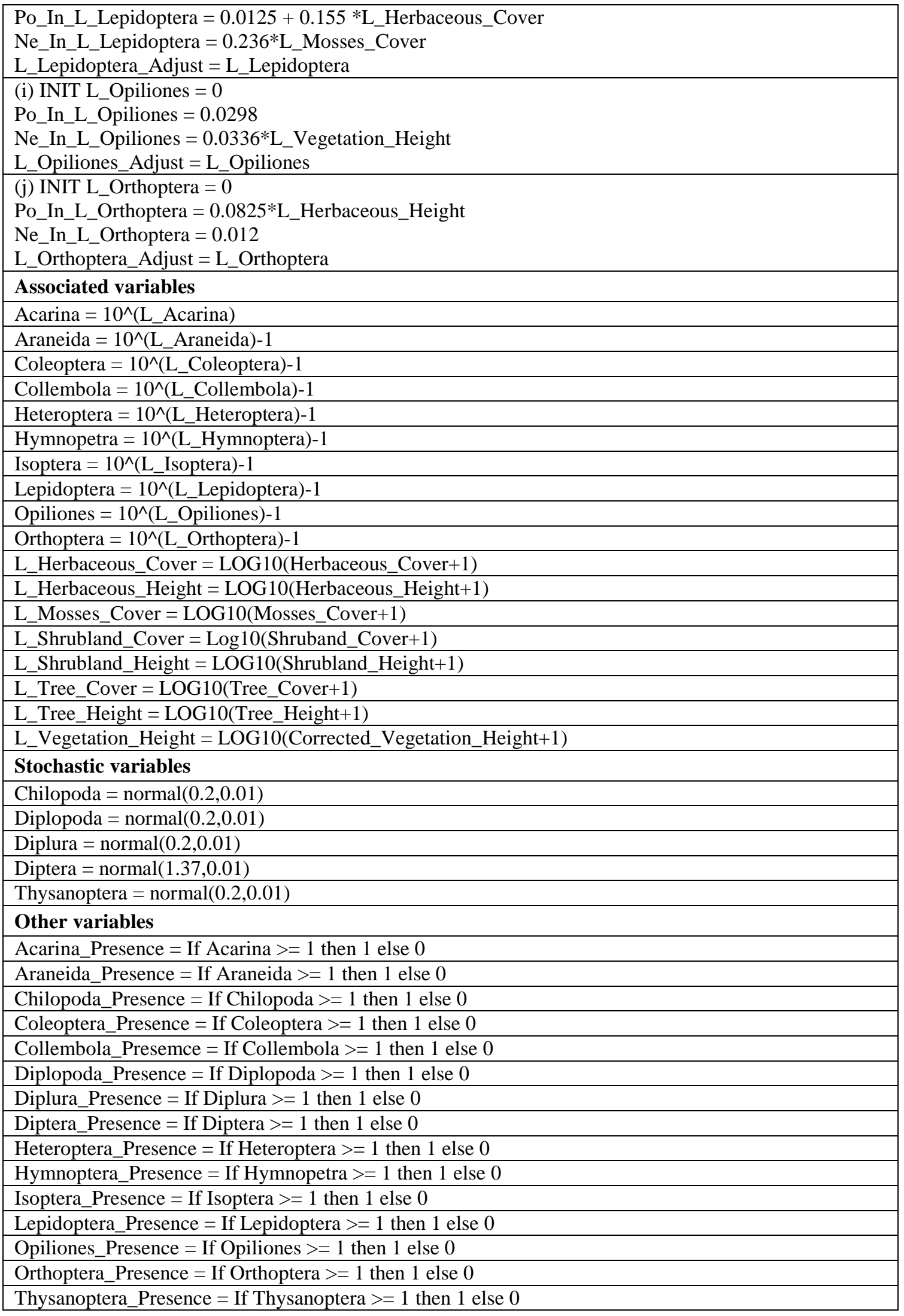




\begin{tabular}{|c|}
\hline Composed variables \\
\hline $\begin{array}{l}\text { Corrected_Vegetation_Height }=\text { If Tree_Height }<\text { Vegetation_Height then Vegetation_Height else } \\
\text { Tree_Height }\end{array}$ \\
\hline Detritivorous_Abundance = Collembola+Diplopoda \\
\hline Detritivorous_Composition = Collembola_Presemce+Diplopoda_Presence \\
\hline Herbivorous_Abundance $=$ Heteroptera+Isoptera+Lepidoptera+Thysanoptera \\
\hline $\begin{array}{l}\text { Herbivoruous_Composition }= \\
\text { Heteroptera_Presence+Isoptera_Presence+Lepidoptera_Presence+Thysanoptera_Presence }\end{array}$ \\
\hline Omnivorous_Abundance $=$ Acarina+Coleoptera+Diplura+Diptera+Hymnopetra+Orthoptera \\
\hline $\begin{array}{l}\text { Omnivorous_Composition }= \\
\text { Acarina_Presence+Coleoptera_Presence+Diplura_Presence+Diptera_Presence+Hymnoptera_Presence+ } \\
\text { Orthoptera_Presence }\end{array}$ \\
\hline Predators_Abundance $=$ Araneida+Chilopoda+Opiliones \\
\hline eida_Presence+Chilopoda_Presence+Opiliones_Presence \\
\hline $\begin{array}{l}\text { Total_Abundance }= \\
\text { Herbivorous_Abundance+Omnivorous_Abundance+Predators_Abundance+Detritivorous_Abundance }\end{array}$ \\
\hline $\begin{array}{l}\text { Total_Composition }= \\
\text { Herbivoruous_Composition+Omnivorous_Composition+Predators_Composition+Detritivorous_Compo } \\
\text { sition }\end{array}$ \\
\hline $\begin{array}{l}\text { Vegetation_Height }=\text { If Herbaceous_Height }>\text { Shrubland_Height then Herbaceous_Height else } \\
\text { Shrubland_Height }\end{array}$ \\
\hline Table functions \\
\hline $\begin{array}{l}\text { Herbaceous_Cover }=\text { GRAPH(time) } \\
(0.00,1.00),(1.05,1.00),(2.11,1.00),(3.16,0.00),(4.21,0.00),(5.26,0.00),(6.32,0.00),(7.37,0.005), \\
(8.42,0.00),(9.47,0.00),(10.5,0.00),(11.6,0.00),(12.6,0.00),(13.7,0.00),(14.7,0.00),(15.8,0.00), \\
(16.8,0.00),(17.9,0.00),(18.9,0.00),(20.0,0.00)\end{array}$ \\
\hline $\begin{array}{l}\text { Herbaceous_Height }=\text { GRAPH(time) } \\
(0.00,1.50),(1.05,1.50),(2.11,1.50),(3.16,0.00),(4.21,0.1),(5.26,0.1),(6.32,0.1),(7.37,0.1),(8.42, \\
0.00),(9.47,0.00),(10.5,0.00),(11.6,0.00),(12.6,0.00),(13.7,0.00),(14.7,0.00),(15.8,0.00),(16.8, \\
0.00),(17.9,0.00),(18.9,0.00),(20.0,0.00)\end{array}$ \\
\hline $\begin{array}{l}\text { Mosses_Cover }=\text { GRAPH(time) } \\
(0.00,0.02),(1.05,0.02),(2.11,0.045),(3.16,0.085),(4.21,0.085),(5.26,0.085),(6.32,0.085),(7.37, \\
0.085),(8.42,0.085),(9.47,0.085),(10.5,0.085),(11.6,0.085),(12.6,0.085),(13.7,0.085),(14.7, \\
0.085),(15.8,0.085),(16.8,0.095),(17.9,0.095),(18.9,0.095),(20.0,0.095)\end{array}$ \\
\hline $\begin{array}{l}\text { Shruband_Cover }=\text { GRAPH(time) } \\
(0.00,0.00),(1.05,0.00),(2.11,0.00),(3.16,0.00),(4.21,0.00),(5.26,0.00),(6.32,0.00),(7.37,0.00), \\
(8.42,0.00),(9.47,0.00),(10.5,0.00),(11.6,0.00),(12.6,0.00),(13.7,0.00),(14.7,0.00),(15.8,0.00), \\
(16.8,0.00),(17.9,0.00),(18.9,0.00),(20.0,0.00)\end{array}$ \\
\hline $\begin{array}{l}\text { Shrubland_Height }=\text { GRAPH(time) } \\
(0.00,0.00),(1.05,0.00),(2.11,0.00),(3.16,0.00),(4.21,0.00),(5.26,0.00),(6.32,0.00),(7.37,0.00), \\
(8.42,0.00),(9.47,0.00),(10.5,0.00),(11.6,0.00),(12.6,0.00),(13.7,0.00),(14.7,0.00),(15.8,0.00), \\
(16.8,0.00),(17.9,0.00),(18.9,0.00),(20.0,0.00)\end{array}$ \\
\hline $\begin{array}{l}\text { Tree_Cover }=\text { GRAPH(time) } \\
(0.00,0.00),(1.05,0.00),(2.11,0.00),(3.16,0.08),(4.21,0.145),(5.26,0.205),(6.32,0.31),(7.37, \\
0.45),(8.42,0.55),(9.47,0.625),(10.5,0.73),(11.6,0.8),(12.6,0.8),(13.7,0.8),(14.7,0.8),(15.8,0.8) \text {, } \\
(16.8,0.8),(17.9,0.8),(18.9,0.8),(20.0,0.805)\end{array}$ \\
\hline
\end{tabular}

